\title{
Pattern of Mandibular Third Molar Impaction and Relationship to the Inferior Alveolar Canal: Retrospective Cone Beam Computed Tomography Analysis in a Group of Sri Lankan
}

\section{Patients}

\section{Medawela RMSHB ${ }^{1}$, Jayasinghe RD $^{1}$ and Wijekoon WMPSK ${ }^{2}$ \\ ${ }^{1}$ Department of Oral Medicine and Periodontology, University of Peradeniya, Sri Lanka ${ }^{2}$ Department of Oral and maxillofacial surgery, University of Peradeniya, Sri Lanka}

*Corresponding author: R.M.S.H.B Medawela, Department of Oral Medicine and Periodontology, Faculty of Dental Sciences, University of Peradeniya, Peradeniya, Sri Lanka, Tel: 0094773344 102; E mail: sumuduhimesha@gmail.com

\section{Research Article}

Volume 3 Issue 2

Received Date: June 04, 2018

Published Date: June 18, 2018

DOI: $10.23880 /$ oajds-16000183

\section{Abstract}

Cone beam computed tomography (CBCT) provides a precise three dimensional analysis of vicinity of Impacted Mandibular third molar (IMTM) which helps in surgical decision making.

Objective: Objective of this study was to analyze the pattern of IMTM and the relationship of inferior alveolar canal to the tooth in 68 patients presented in year 2014 University Dental Hospital, Sri Lanka.

Methods: The study sample included 112 IMTM teeth in 68 patients ( $54.5 \%$ females, $45.5 \%$ males) with average age of 28 years. Preoperative radiological assessment of IMTM was carried out with the aim of analyzing relationship of inferior alveolar canal to the roots of IMTM, analyzing their morphology, predicting anticipated difficulty in exodontia of IMTM and complications such as damaging the inferior alveolar nerve

Results: Pell and Gregory Class I B pattern of impaction was predominant in the sample with mesioangular impaction being the most commonly occurring angulation of impaction. The Inferior alveolar canal was placed on buccal aspect of root apex in $35.7 \%$ of cases whereas in $33.9 \%$ of cases it was lingually placed.

Conclusion: In conclusion the Pattern of impaction and the morphology of IMTM in current study comply with international norms except in few aspects.

Keywords: Impacted mandibular third molar; Cone beam CT; Inferior alveolar canal position; Morphology 


\section{Open Access Journal of Dental Sciences}

Abbreviations: CBCT: Cone beam computed tomography; IMTM: Impacted Mandibular Third Molar; IOPA: Intra Oral Peri Apical Radiograph.

\section{Introduction}

Impacted Mandibular third molar (IMTM) tooth is one of the most commonly impacted tooth of the dental arch [1-3] with a frequency of occurrence range from 18-32 \% $[1,2]$ with slight female predilection $[1,4]$. Tooth arch size discrepancy leading to inadequate space for the eruption of IMTM had been identified as most common cause for this phenomenon. IMTM may associate diversified clinical presentations and pericoronitis, swelling in the region, associated odotogenic cysts and tumours, bone resorption and resorption in adjacent tooth are some of them [5]. Such complications are usually associated with impaired oral functions and further leading to discomfort [5].

Surgical removal of impacted third molar is one of the most commonly practiced surgical procedures in the inpatient and outpatient oral and maxillofacial surgical units. As in any other surgical procedure surgical removal of impacted third molar may result intra operative and post operative complications. Surgical site infection, limitation in mouth opening and neurological complications such as damage to inferior alveolar nerve and lingual nerve are commonly encountered. Further fracture of lingual plate, dislodgement of root pieces in to facial spaces, mandibular fractures, infections in submandibular and pterygomandibular spaces are rarely seen in the clinical practice [5-7].

In Surgical removal of IMTM, radiological analysis plays an utmost important role in careful preoperative assessment with the intention of minimizing complications. Cone beam computed tomography (CBCT) provides a precise three dimensional analysis of vicinity of impacted third molar and it is observed to be the main advantage of this imaging modality compared to conventional panaromic radiographs [8-11]. In surgical perspective review of literature highlights several important aspects to consider in assessment of impacted mandibular third molar. Surgical technique, method of anesthesia, patient age, position of the third molar, angulation and depth of impaction, relationship between the mandibular canal and the third molar, Curvature and other morphological aspects of roots and Shape of inferior alveolar canal were considered to be the factors that influential in predicting nerve damage [5-7].
Ideology of the current study was evolved with the observations of authors during their routine radiological investigations of IMTM. Deviations in patterns of mandibular third molar impaction and its relationship to inferior alveolar nerve from literature had been noted and attempted to explore in the current study.

Objective of this study was to analyze the pattern of IMTM and the relationship of inferior alveolar canal to the tooth. Study of basic morphological aspects of crown and roots were carried out as a specific objective.

\section{Materials and Methods}

Retrospective analysis was carried out in 68 patients with IMTM presented in year 2014 to division of Oral Medicine and Radiology for preoperative CBCT assessment. Data were retrieved from archives of division of Oral Medicine and Radiology. Patients age, gender and impacted tooth (whether it is 38 or 48 ) were obtained from the records. Patients above 18 years with IMTM or IMTM with definite future impaction predicted by consultant Oral and maxillofacial surgeon and Oral and maxillofacial radiology expert, were included in the study population.

CBCT's with poor image quality were excluded from the study. Further patients presented with acute symptoms were excluded from the study. All these patients were routinely screened and IMTM was assessed with intra oral peri apical radiograph (IOPA). When features of IOPA radiograph predicts the risk of damage to inferior alveolar nerve to be high, CBCT was carried out to assess the definite risk. All CBCT mandibular scans were acquired using VATECH PAX-DUO 3D system with focal spot of $0.5 \mathrm{~mm}$ and CMOS sensor. All images analyzed using Ez3D plus visualizer software. CBCT scans of IMTM teeth were reassessed in coronal, axial, sagittal views and pseudo dental panaromic tomogram view in a plane bisecting the tooth as well as the second molar tooth mesio-distally.

Pattern of impaction was determined according to PELL and GREGORY classification of impacted third molar [2] and categorization of angulation of impacted third molar done in accordance with modified Winters classification adopted by Quek SL, et al. [1] in 2003. The angulation of impaction was determined by the angle formed between the intersected longitudinal axes axis of the second and third molar teeth. Determination of angle was done as Table 1. 


\section{Open Access Journal of Dental Sciences}

\begin{tabular}{|c|c|}
\hline Type of impaction & $\begin{array}{c}\text { Angle formed between intersected longitudinal axes of second and third } \\
\text { molar teeth }\end{array}$ \\
\hline Vertical impaction & $10^{\circ}$ to $-10^{\circ}$ \\
\hline Mesioangular impaction & $11^{\circ}$ to $79^{\circ}$ \\
\hline Horizontal impaction & $80^{\circ}$ to $100^{\circ}$ \\
\hline Distoangular impaction & $-11^{\circ}$ to $-79^{\circ}$ \\
\hline Others & $111^{\circ}$ to $-80^{\circ}$ \\
\hline Buccolingual impaction & \\
\hline
\end{tabular}

Table 1: Angulation of impaction (note that the positive angulation indicates mesio angulation and negative angulation indicates distoangulation).

In addition, depth of impaction (Figure 1), Position of inferior alveolar canal (Figure 2), Distance from root apex to the wall of the canal (Figure 3) and presence of flattening of the canal (Figure 4) were also recorded.

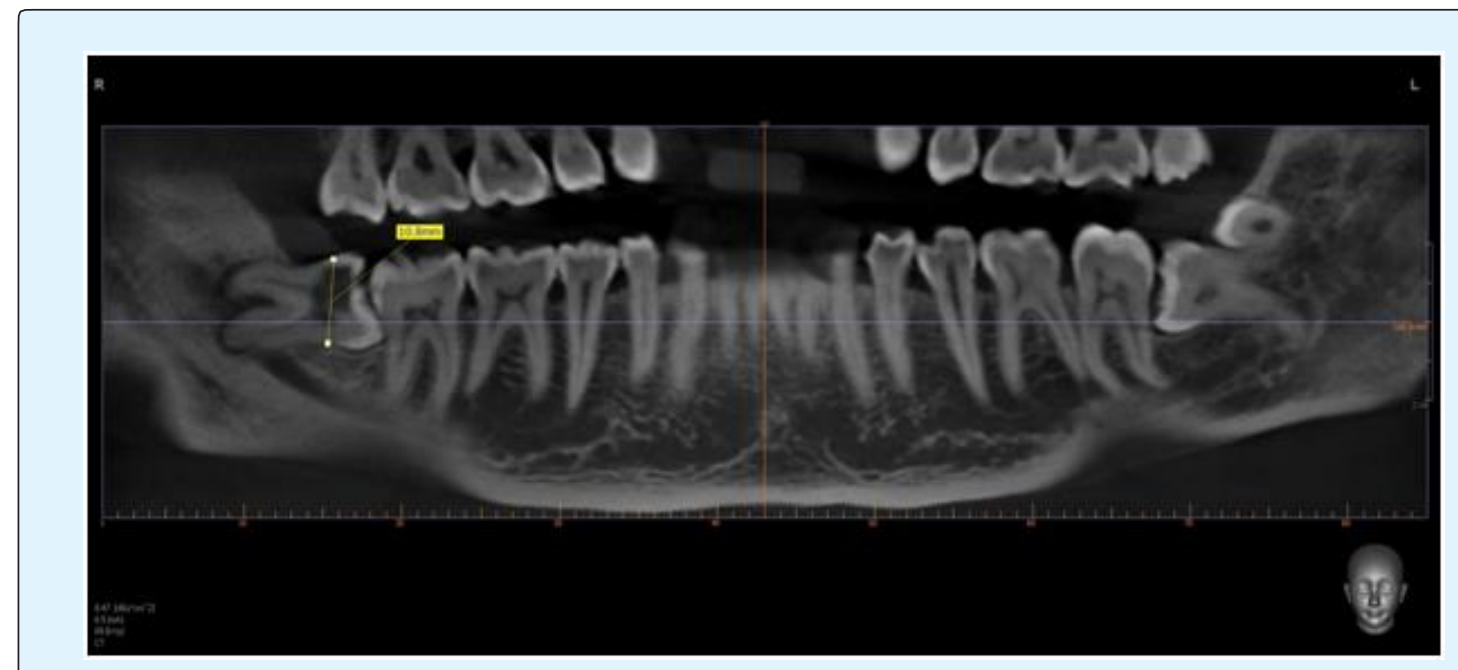

Figure 1: Depth of Impaction: Distance from point of application to white line (Occlusal plane).

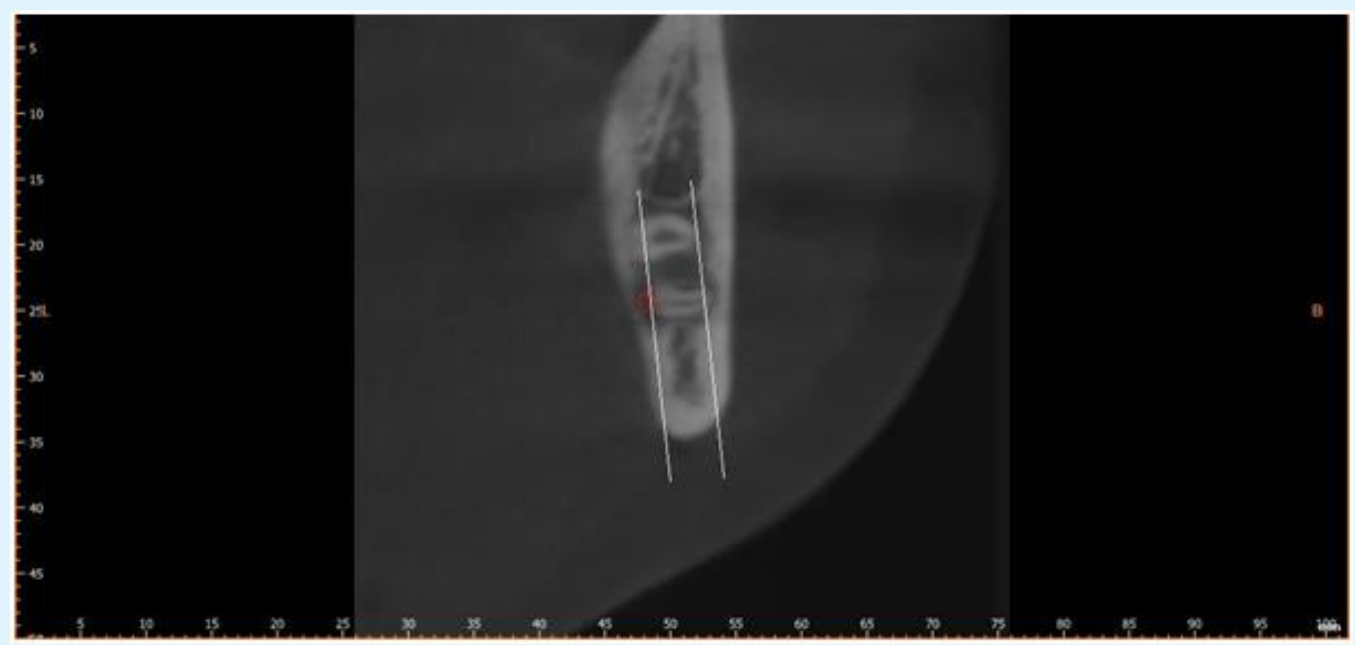

Figure 2: Position of inferior alveolar canal: Either lingually positioned, apically positioned or bucally positioned. 


\section{Open Access Journal of Dental Sciences}

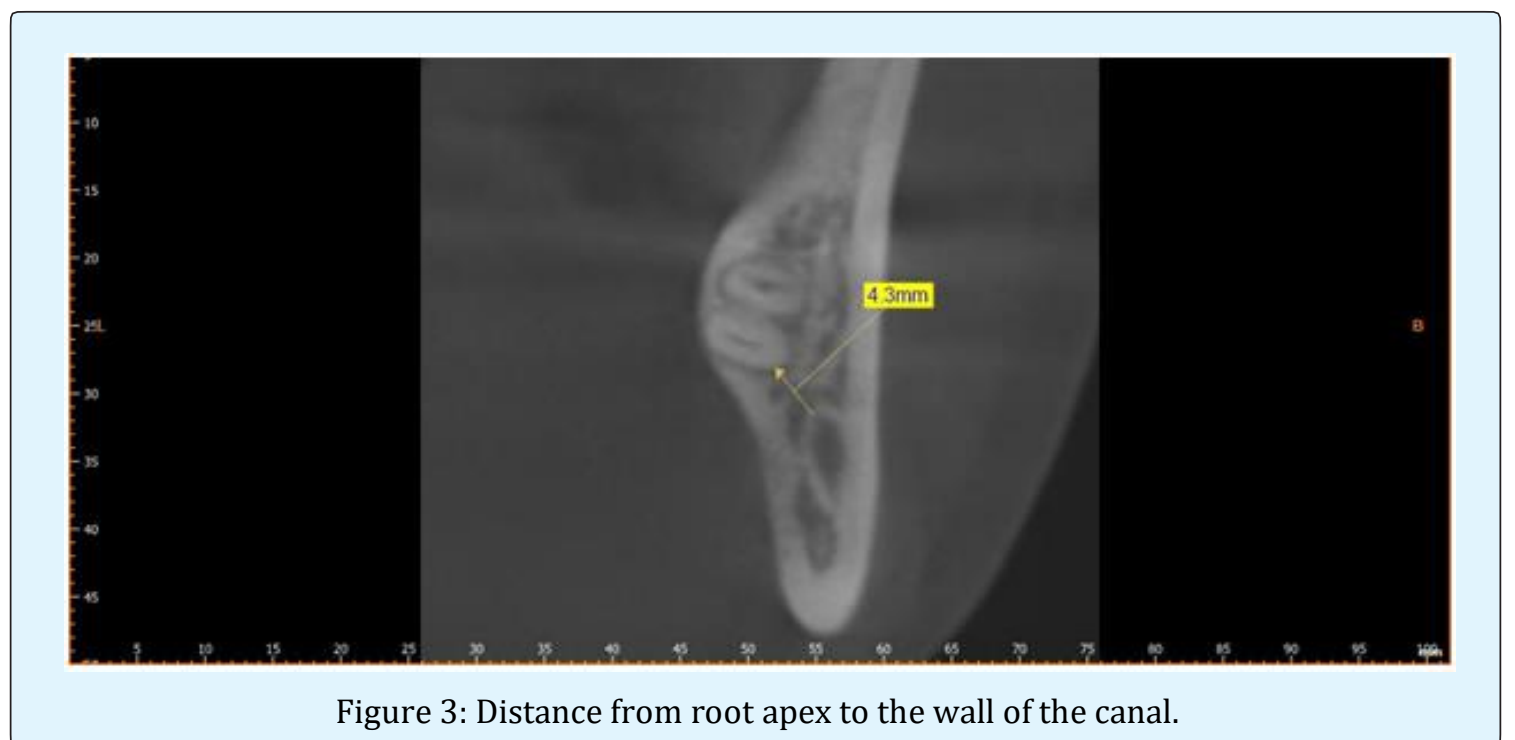

Figure 3: Distance from root apex to the wall of the canal.

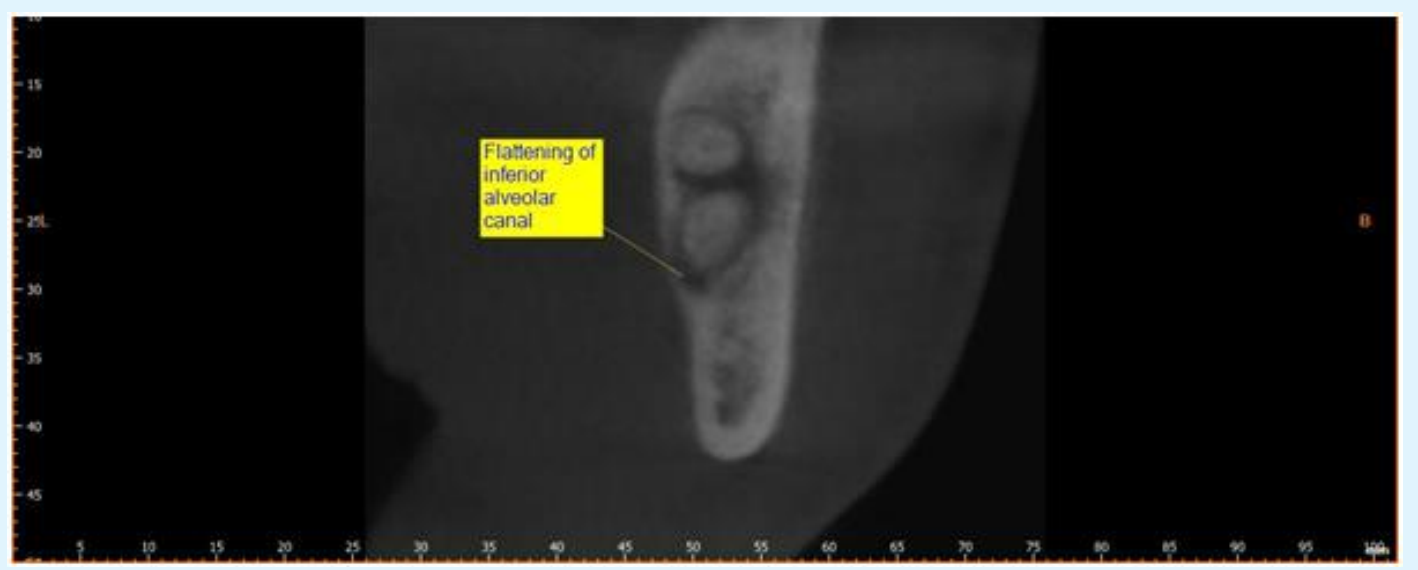

Figure 4: Presence of flattening of the canal.

Morphological aspects of IMTM such as dimensions of the tooth (Mesio-distal length at the lengthiest point and Bucco-lingual width at the widest point) and features of the roots were also recorded (either Divergent or Convergent: This was analyzed in relation to the width of the roots at its origin. During its course if width of the two roots exceeds the width at the origin of the roots were considered divergent, if not convergent).

Data was analyzed using Microsoft excel 2010 and descriptive statistics for all variables computed.

\section{Results}

The study sample included 112 IMTM teeth in 68 patients in which $54.5 \%$ were female and $45.5 \%$ were males. Average age of the subjects with IMTM was 28 years with the age range of 19 to 44 years. Occurrence of different patterns of impactions is shown in Table 2.

\begin{tabular}{|c|c|c|c|}
\hline & A & B & C \\
\hline Class I & 17 & 24 & 1 \\
\hline Class II & 14 & 16 & 3 \\
\hline Class III & 6 & 17 & 14 \\
\hline
\end{tabular}

Table 2: Pattern of impaction in accordance with Pell and Gregory classification.

Occurrences of different angulations of impactions are mentioned in Table 3. 


\section{Open Access Journal of Dental Sciences}

\begin{tabular}{|c|c|}
\hline Angulation of impaction & Number of cases \\
\hline Mesio angular & 62 \\
\hline Vertical & 22 \\
\hline Distoangular & 11 \\
\hline Horizontal & 16 \\
\hline Other (Mesio inverted) & 1 \\
\hline
\end{tabular}

Average depth of impaction was recorded to be $10.23 \mathrm{~mm}$.

Relationship of the roots with inferior alveolar canal (IAC) is shown in Table 4.

Table 3: Angulation of impaction in accordance with modified Andreson classification.

\begin{tabular}{|c|c|c|c|c|}
\hline $\begin{array}{c}\text { Position of IAC Placed Lingual, } \\
\text { Buccal, Apically Through root }\end{array}$ & No of Cases & $\begin{array}{c}\text { Proximity of tooth to Inferior } \\
\text { Alveolar Canal in mm average }\end{array}$ & Range & $\begin{array}{c}\text { No of cases with Canal } \\
\text { flattening }\end{array}$ \\
\hline Lingual & 38 & $0.3 \mathrm{~mm}$ & $0-1.2$ & 27 \\
\hline Buccal & 40 & $2.2 \mathrm{~mm}$ & $0-7.8$ & 3 \\
\hline Apical & 31 & $1.44 \mathrm{~mm}$ & $0-3.7$ & 2 \\
\hline Through & 3 & & & 0 \\
\hline
\end{tabular}

Table 4: Relationship of the root with inferior alveolar canal.

Basic aspects of morphology were studied additionally and the results were indicated on the Table 5.

\begin{tabular}{|c|c|c|}
\hline Average Mesial-Distal width & & $11.15 \mathrm{~mm}$ \\
\hline Average Bucco- lingual width & & $10.18 \mathrm{~mm}$ \\
\hline Number of roots & 1 Root & 2 IMTM \\
\hline & 2 Roots & 103 IMTM \\
\hline Root shape & 3 Roots & 7 IMTM \\
\hline & Convergent & 80 IMTM \\
\hline Root Fused Yes or No & Divergent & 32 IMTM \\
\hline Presence of sharp curve in the root & Fused & 28 IMTM \\
\hline Condition of Second molar & Not fused & 84 IMTM \\
\hline & & $36 / 112$ IMTM \\
\hline & Absent & 2 \\
\hline & Normal & 68 \\
\hline & Carious & 23 \\
\hline
\end{tabular}

Table 5: Morphological aspects of IMTM.

\section{Discussion}

Preoperative radiological assessment of IMTM is carried out with the aim of predicting anticipated difficulty in exodontia of IMTM and complications specifically the damage to inferior alveolar canal $[10,12]$. The four most common post-operative complications reported in the literature are Alveolar osteitis, infection, bleeding and paresthesia. Effectiveness of CBCT in assessment of IMTM and its relationship to the inferior alveolar canal has been demonstrated in several studies around the world $[3,8,9,11-13]$.
As in worldwide literature greater frequency of IMTM occurrence in female is observed in this study with a male to female to male ratio of $1: 0.83$ [1].

Mesiangular impaction was recorded to be the most common impaction with the percentage of occurrence of $55.3 \%$ as in the study done by Quek SL, et al. [1] in 2003 in a Singapore Chinese population [1]. This trend was observed in several other studies done around the world but sound conclusions cannot be drawn on the prevalence of angulation of impaction as heterogeneity of angulation determining criteria. 


\section{Open Access Journal of Dental Sciences}

Worldwide studies done with the intention of determining the pattern of impaction the group A was found to be the commonest. However as in study done by Queck, et al. in Singapore Chinese population, our sample also demonstrated the Group B as commonest. Further the Class I impaction predominates as in literature, Class IB being the commonest.

Position of canal in buccal aspect of root was found in $35.7 \%$ of the cases and around 31\% of them showed canal flattening. Worldwide literature suggested that inferior alveolar canal lying on the lingual side to more prominent [12]. This is an important finding elicited in the study as in surgical removal of IMTM involves removal of bone mainly in the buccal aspect of the tooth. Therefore extreme care should be made not to remove excessive bone and not to drive the rotary instruments deeply, as buccally positioned inferior alveolar canal is in risk of trauma during surgery.

However inferior alveolar canal travelling through the roots of IMTM which the radiological finding is classified as very high risk for the never nerve damage during surgical exodontia was observed only in 3 cases $(0.03 \%)$.

\section{Conclusion}

With a female predominance, Mandibular impacted third molar was commonly observed to be with the pattern of Class I B in Pell and Gregory classification. However, the reported radiological risk to be very high. was observed in only 3 cases of IMTM among 112 cases. CBCT play a major role in precise analysis of the IMTM and avoids most of the defects in two dimensional tomography.

\section{References}

1. Quek SL, Tay CK, Tay KH, Toh SL, Lim KC (2003) Pattern of third molar impaction in a Singapore Chinese population: a retrospective radiographic survey. Int J Oral Maxillofac Surg 32(5): 548-552.

2. Obiechina AE, Arotiba JT, Fasola AO (2001) Third molar impaction: evaluation of the symptoms and pattern of impaction of mandibular third molar teeth in Nigerians. Odontostomatol Trop 24(93): 22-25.

3. Koong B, Pharoah MJ, Bulsara M, Tennant M (2006) Methods of determining the relationship of the mandibular canal and third molars: a survey of
Australian oral and maxillofacial surgeons. Aust Dent 51(1): 64-68.

4. Hassan AH (2010) Pattern of third molar impaction in a Saudi population. Clin Cosmet Investig Dent 2: 109113.

5. Wang D, Xiaotong He, Yanling Wang, Guangchao Zhou, Chao Sun, et al. (2016) Topographic relationship between root apex of mesially and horizontally impacted mandibular third molar and lingual plate: cross-sectional analysis using CBCT. Sci Rep 6: 39268.

6. Nakagawa $\mathrm{Y}$, Ishii $\mathrm{H}$, Nomura $\mathrm{Y}$, Watanabe NY, Hoshiba D, et al. (2007) Third molar position: reliability of panoramic radiography. J Oral Maxillofac Surg 65(7): 1303-1308.

7. Susarla SM, Dodson TB (2004) Risk factors for third molar extraction difficulty. J Oral Maxillofac Surg 62(11): 1363-1371.

8. Tantanapornkul W, Okochi K, Bhakdinaronk A, Ohbayashi N, Kurabayashi T (2009) Correlation of darkening of impacted mandibular third molar root on digital panoramic images with cone beam computed tomography findings. Dentomaxillofac Radiol 38(1): 11-16.

9. Tantanapornkul W, Okouchi K, Fujiwara Y, Yamashiro M, Maruoka Y, et al. (2007) A comparative study of cone-beam computed tomography and conventional panoramic radiography in assessing the topographic relationship between the mandibular canal and impacted third molars. Oral Surg Oral Med Oral Pathol Oral Radiol Endod 103(2): 253-259.

10. Bui CH, Seldin EB, Dodson TB (2003) Types, frequencies, and risk factors for complications after third molar extraction. J Oral Maxillofac Surg 61(12): 1379-1389.

11. Pawelzik J, Cohnen M, Willers R, Becker J (2002) A comparison of conventional panoramic radiographs with volumetric computed tomography images in the preoperative assessment of impacted mandibular third molars. J Oral Maxillofac Surg 60(9): 979-984.

12. Ghaeminia H, Meijer GJ, Soehardi A, Borstlap WA, Mulder J, et al. (2009) Position of the impacted third molar in relation to the mandibular canal. Diagnostic accuracy of cone beam computed tomography compared with panoramic radiography. Int J Oral Maxillofac Surg 38(9): 964-971. 